\title{
Development and Validation of Stability-Indicating HPLC-DAD Method for Simultaneous Determination of Emtricitabine, Elvetegravir, Cobicistat and Tenofovir in their Tablet Dosage Forms
}

\author{
Mallikarjuna rao Nagasarapu ${ }^{1 *}$ and Gowri Sankar Dannana ${ }^{2}$ \\ ${ }^{*}$ Department of Pharmaceutical Sciences, Jawaharlal Nehru Technological University, Kakinada, Andhra Pradesh, India. \\ ${ }^{2}$ Department of Pharmaceutical Analysis \& Quality Assurance, University College of Pharmaceutical Sciences, Andhra University, \\ Visakhapatnam, Andhra Pradesh, India.
}

\begin{abstract}
A Simple, accurate, specific and rugged reverse phase liquid chromatographic method was developed for the simultaneous estimation of Emtricitabine, Elvetigravir, Cobicistat and Tenofovir in bulk and tablet dosage form. A reverse phase gradient program has been developed to separate the all four active ingredients. The mobile phase consisting of $0.05 \mathrm{M}$ Phosphate buffer $\mathrm{pH} 3.0$ (adjusted with dilute phosphoric acid) and Acetonitrile in the ratio $95: 5$ from $0 \mathrm{~min}$ to 4 minutes, further increased the Acetonitrile ratio from 5 to 50 from 4 min to 10 minutes, on a reverse phase $C_{18}$ column $(250 \times 4.6 \mathrm{~mm}, 5 \mu)$ with a flow rate of $1.0 \mathrm{ml} / \mathrm{min}$, monitored at 240nm. The mean retention times of Emtricitabine, Elvetigravir, Cobicistat and Tenofovir were found to be 1.5 , 5.4, 6.6 and 7.5 min respectively. The proposed method was validated in terms of Linearity, Range, Accuracy, Precision, Specificity, Robustness and Ruggedness and the method was successfully applied for the estimation of Emtricitabine, Elvetigravir, Cobicistat and Tenofovir in combined tablet dosage form.
\end{abstract}

Key words: Emtricitabine, Elvetigravir, Cobicistat, Tenofovir, HPLC-DAD, Tablet.

\section{INTRODUCTION}

Emtricitabine (EMCB) is a nucleoside reverse transcriptase inhibitor (NRTIs). Chemically it is 5-fluoro-1-(2R,5S)[2-(hydroxymethyl)-1,3-oxathiolan-5-yl] cytosine (Figure 1). EMCB is the (-) enantiomer of thio analog of cytidine which differs from other cytidine analogs, in that it has a fluorine in 5th position. EMCB is an antiviral agent used for the prevention of perinatal HIV-1 reverse transcriptase. ${ }^{1}$ It is also active against Hepatitis B virus. ${ }^{2,3}$

Elvitegravir (ELVT) is a drug used for the treatment of HIV infection. It acts as an integraseinhibitor.Chemical nameof Elvitegravir is 6-[(3- Chloro-2- fluorophenyl) methyl]1-[(2S)-1 - hydroxy-3- methylbutan-2 -yl]- 7-methoxy- 4-oxoquinoline-3- carboxylic acid (Figure 1). Elvitegravir acts as an integrase inhibitor. According to the results of the phase II clinical trial, patients taking once-daily Elvitegravir boosted by ritonavir had greater reductions in viral load after 24 weeks compared to individuals randomized to receive a ritonavir-boosted protease inhibitor. $^{4}$

Cobicistat $(\mathrm{COB})$ is a licensed drug for use in the treatment of infection with the human immunodeficiency virus (HIV). Cobicistat acts as an HIV integrase inhibitor. Chemical name of Cobicistat is Thiazol-5-ylmethyl $N$-[1-benzyl-4-[[2-[[(2-isopropylthiazol4-yl) methyl-methyl-carbamoyl] amino]-
Submission Date : 03-12-2014 Revision Date : :22-06-2015 Accepted Date : :19-07-2015

DOI: 10.5530/ijper.50.1.25 Correspondence Address Mallikarjuna Rao

E-mail: mallimpharmmba@ gmail.com

Phone: +91-9030470834.

\section{Co-author:}

D. Gowri Sankar

Email: gowrisankar97@

rediffmail.com

Phone: +91-9441013695

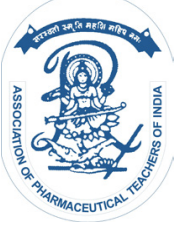

www.ijper.org 
4-morpholinobutanoyl] amino]-5-phenyl-pentyl] carbamate (Figure 1). Cobicistat is the only other booster approved for use as a part of HAART, Cobicistat has no anti- HIV activity of its own. Cobicistat is a potent inhibitor of cytochrome P450 3A enzymes, including the important CYP3A4 subtype. It also inhibits intestinal transport proteins, increasing the overall absorption of several HIV medications, including atazanavir, darunavir and Tenofovir disoproxil fumarate alafenamide fumarate. ${ }^{5-6}$

Tenofovir disoproxil fumarate (TDF) belongs to a class of antiretroviral drugs known as nucleotide analogue reverse transcriptase inhibitors (NRTIs). Tenofovir disoproxil fumarate is a prodrug form of Tenofovir disoproxil fumarate. Chemical name of Tenofovir disoproxil fumarate is $(\{[(2 R)-1-(6-$ amino- $9 H$-purin-9-yl) propan-2-yl] oxy 3 methyl) phosphonic acid (Figure.1). Tenofovir disoproxil fumarate blocks reverse transcriptase, a crucial virus enzyme in human immunodeficiency virus 1 (HIV-1) and hepatitis B virus infections. Tenofovir disoproxil fumarate exhibits anti-HIV effects in humans when dosed by subcutaneous injection. Tenofovir disoproxil fumarate is indicated for the treatment of chronic hepatitis B in adults and pediatric patients 12 years of age and older. ${ }^{7-9}$

A survey of literature has revealed several analytical methods for the determination of Tenofovir and EMCB in combination with efavirenz in biological fluids and in pharmaceutical products. These include high-performance liquid chromatography (HPLC)..$^{10-11}$ On the contrary, to the best of our knowledge, there is no method reporting the simultaneous determination of TDF, ELVT, COB, and EMCB in pharmaceutical formulation. In this paper, we report the very first reversed-phase-HPLC (RP-HPLC) method for the assay of EMCB, ELVT, TDF, and COB in fixed dosage form. The new method is capable of separating all four active

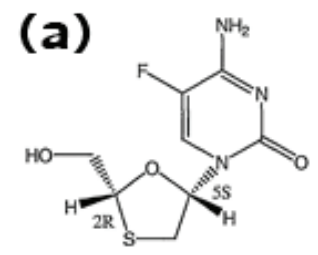

(b)
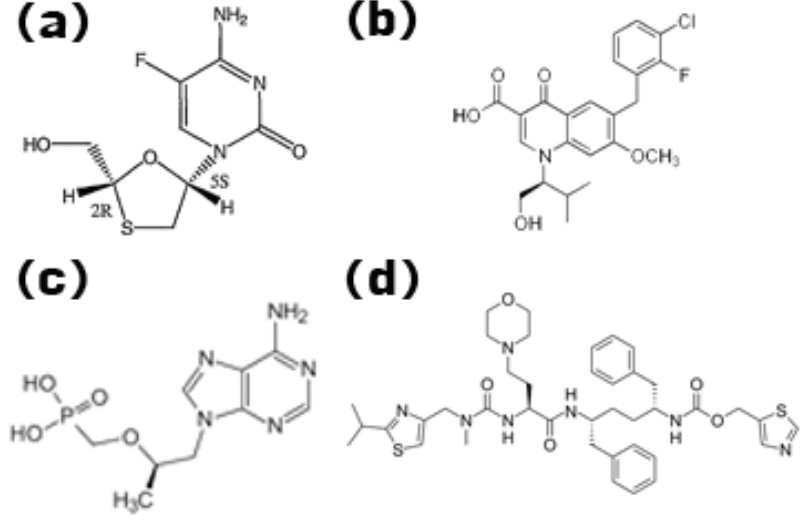

Figure 1: Chemical structures of a) Emtricitabine, b) Elvitegravir, c) Cobicistat , d) Tenofovir disoproxyl fumarate ingredients present in the tablet. Validation of the current method will be performed according to the requirements of International Conference on Harmonization $(\mathrm{ICH})$ for assay determination which include accuracy, precision, selectivity, linearity and range.

Several HPLC methods are available in the literature for individual drugs and for a combination with other drugs for determination of TDF, FTC, and EFV, but no stability-indicting assay method (SIAM) has been reported. ${ }^{12-27}$ Few RP-HPLC ${ }^{28-29}$ methods are reported for estimation of FTC and TDF in pharmaceutical formulation. The literature survey revealed that there are a very few HPLC and spectroscopic methods available for the determination of Emtricitabine, Tenofovir disoproxil fumarate, Cobicistat, Elvitegravir in pure and combined dosage forms. The present study was aimed to develop a new HPLC method for simultaneous estimation of Emtricitabine, Tenofovir disoproxil fumarate, Cobicistat, Elvitegravir in combined pharmaceutical dosage form.

\section{Experimental Materials}

The Pharmaceutical grade working standards of Emtricitabine, Elvetigravir, Cobicistat and Tenofovir were obtained as a gift from Richer Pharmaceuticals (Prasanthinagar, Hyderabad, India). Fixed dosage combination tablet containing $200 \mathrm{mg}$ Emtricitabine, 150 $\mathrm{mg}$ Elvetigravir, $150 \mathrm{mg}$ Cobicistat and $300 \mathrm{mg}$ Tenofovir was purchased from local market Hyderabad, India. All the chemicals were HPLC grade purchased from SD Fine Chem., Mumbai. MilliQ water was used.

\section{Chromatographic Conditions}

Waters e 2695 series HPLC consisting pump, Auto sampler, Auto injector, VWD \& photo diode array detector, thermostatic column compartment connected with Empower 2 software connected with a Hypersil $\mathrm{BDS} \mathrm{C}_{8} 250 \mathrm{x} 4.6 \mathrm{~mm}, 5 \mu, 100 \mathrm{~A}$.

\section{Mobile phase}

Accurately weighed $6.8 \mathrm{~g}$ of potassium dihydrogen orthophosphate in $1000 \mathrm{ml}$ of water, adjusted $\mathrm{pH} 3.0$ with diluted phosphoric acid. Filtered the solution through $0.22 \mu$ nylon filter and sonicated to degas it. The buffer was used as mobile phase preparation A, Acetonitrile used as mobile phase mobile preparation B, Emtricitabine, Elvetigravir, Cobicistat and Tenofovir were separated and eluted in a gradient program represented in Table 1. The flow rate of the mobile phase was maintained at $1.0 \mathrm{ml} / \mathrm{min}$. The column temperature was maintained at $30^{\circ} \mathrm{C}$ and the detection was carried out at $240 \mathrm{~nm}$ with an injection volume of $20 \mu \mathrm{l}$. 


\begin{tabular}{|c|c|c|c|}
\hline \multicolumn{4}{|c|}{ Table 1: Gradient Table } \\
\hline Time(mins) & $\begin{array}{c}\text { Mobile } \\
\text { Phase A }\end{array}$ & $\begin{array}{c}\text { Mobile } \\
\text { Phase B }\end{array}$ & Mode \\
\hline 0 & 95 & 5 & Isocratic \\
\hline 4 & 95 & 5 & Isocratic \\
\hline 10 & 50 & 50 & Linear gradient \\
\hline 15 & 95 & 5 & Linear gradient \\
\hline 20 & 95 & 5 & Isocratic \\
\hline
\end{tabular}

\section{Standard solution preparation}

Weighed accurately working standards equivalent to 20 mg Emtricitabine, $15 \mathrm{mg}$ Elvetigravir, $15 \mathrm{mg}$ Cobcistat and $30 \mathrm{mg}$ Tenofovir into $50 \mathrm{ml}$ volumetric flask, added $30 \mathrm{ml}$ of diluent and dissolved, further made the volume with the diluent. Further diluted $10 \mathrm{ml}$ to $100 \mathrm{ml}$ with mobile phase.

\section{Sample preparation}

Crushed to powder 20 tablets, weighed and transferred equivalent to 1 tablet powder into $500 \mathrm{~mL}$ volumetric flask added $300 \mathrm{~mL}$ of diluent, sonicated to dissolve for 10 minutes and diluted to volume with diluent. Further filtered the solution through $0.22 \mu$ filter. Diluted $10 \mathrm{ml}$ to $100 \mathrm{ml}$ with diluent.

\section{RESULTS AND DISCUSSION}

\section{Method development and optimization of chromatographic conditions}

In order to achieve good separation between all the four components different buffer $\mathrm{pH}$-conditions and different proportions of solvents like methanol, Acetonitrile and water tested binary and tertiary eluents. However, in $0.05 \mathrm{M}$ phosphate buffer $\mathrm{pH} 3.0$ adjusted $\mathrm{pH}$ with dilute phosphoric acid and Acetonitrile achieved good satisfactory results at a flow rate of $1.0 \mathrm{ml} /$ minute measured at a détection of $240 \mathrm{~nm}$. The chromatogram of optimized standard mixture chromatogram shown in Figure 2. The system suitability paramètres such as rétention time, assymetry, resolution and theoritical plates for optimized standard mixture chromatogram tabulated in Table 2 .

\section{Method Validation}

\section{System| suitability}

System suitability is an integral part of the method validation to evaluate the parameters like tailing factor, theoretical plates, resolution and \%RSD for replicate injections. The results were within the limits and were presented in Table 2. Figure 2 shows the system suitability chromatogram.

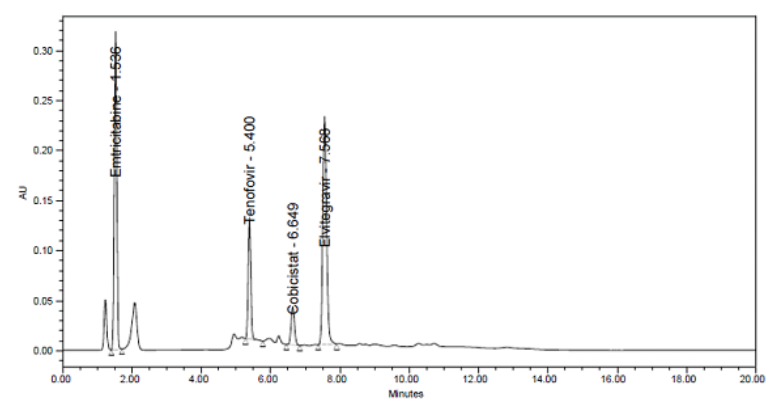

Figure 2. System suitability chromatogram

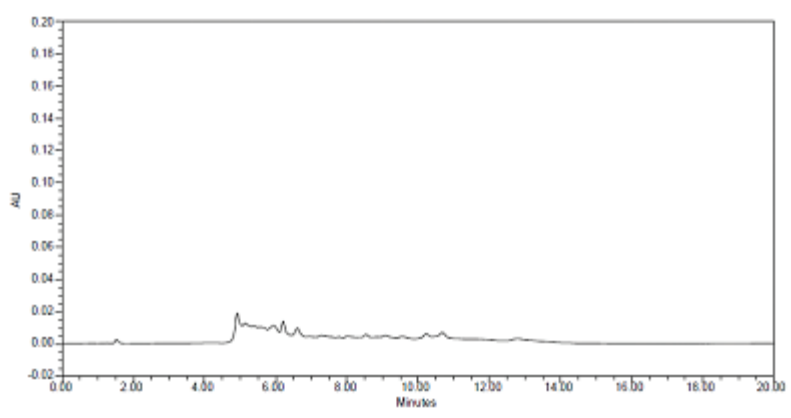

Figure 3: Blank chromatogram

\section{Specificity}

In the placebo chromatogram there were no peaks observed at the retention times of Emtricitabine, Elvetigravir, Cobicistat and Tenofavir, and also the degradation studies showed that there no interference with degradants and hence the method was specific. Figure 3 shows placebo chromatogram.

\section{Accuracy}

To determine the Accuracy of the proposed method, recovery studies were conducted; known amount of pure drug concentrations was spiked in placebo at three different levels, ie, $50 \%, 100 \%$ and $150 \%$ and was calculated. Accuracy was calculated as the percentage of recovery. The results were tabulated in Table 3.

\section{Precision}

The precision was evaluated at three levels, repeatability, reproducibility and intermediate precision each level of precision was investigated by six replicate injections of concentrations 40, 30, 30 and $60 \mathrm{mcg} / \mathrm{ml}$ Emtricitabine, Elvetigravir, Cobicistat and Tenofavir respectively. The result of precision was expressed as \% of RSD and was tabulated in Table 4.

\section{Linearity and range}

The linearity was evaluated by measuring different concentrations (25\% to $150 \%$ ) of the standard solutions to Emtricitabine, Elvetigravir, Cobicistat and Tenofavir. 
Table 2: System suitability results

\begin{tabular}{|c|c|c|c|c|c|}
\hline \multirow{2}{*}{ Parameter } & \multicolumn{4}{|c|}{ Results } & \multirow{2}{*}{ Required limits } \\
\cline { 2 - 5 } & Emtricitabine & Elvetigravir & Cobicistat & Tenofovir & $<2.0$ for $\mathrm{n} \geq 6$ \\
\hline RSD of peak area & 0.11 & 0.09 & 0.55 & 0.19 & $<1.0$ for $\mathrm{n} \geq 6$ \\
\hline RSD of retention time & 0.13 & 0.07 & 0.05 & 0.03 & $\mathrm{~T}<2$ \\
\hline USP Tailing factor (T) & 0.98 & 1.13 & 1.07 & 1.10 & $>2000$ \\
\hline USP Plate Count (N) & 2985 & 23045 & 21851 & 22687 & $\mathrm{R}>2$ \\
\hline USP Resolution (R) & - & 4.74 & 7.61 & 27.58 & \\
\hline
\end{tabular}

\begin{tabular}{|c|c|c|c|c|}
\hline Parameter & $\begin{array}{c}\text { Amount } \\
\text { added }(\mu \mathrm{g})\end{array}$ & $\begin{array}{c}\text { Amount } \\
\text { Recovered }(\mu \mathrm{g})\end{array}$ & $\begin{array}{c}\% \text { of } \\
\text { recovery }\end{array}$ & Mean \% of Recovery \\
\hline \multicolumn{5}{|c|}{ Emtricitabine } \\
\hline $50 \%$ level & 20 & 19.992 & 99.96 & \multirow{3}{*}{99.54} \\
\hline $100 \%$ level & 40 & 39.888 & 99.72 & \\
\hline $150 \%$ level & 60 & 59.37 & 98.95 & \\
\hline \multicolumn{5}{|c|}{ Elvetigravir } \\
\hline $50 \%$ level & 15 & 14.898 & 99.32 & \multirow{3}{*}{100.04} \\
\hline $100 \%$ level & 30 & 29.97 & 99.90 & \\
\hline $150 \%$ level & 45 & 45.41 & 100.91 & \\
\hline \multicolumn{5}{|c|}{ Cobicistat } \\
\hline $50 \%$ level & 15 & 14.83 & 98.89 & \multirow{3}{*}{99.39} \\
\hline $100 \%$ level & 30 & 30.04 & 100.14 & \\
\hline $150 \%$ level & 45 & 44.61 & 99.14 & \\
\hline \multicolumn{5}{|c|}{ Tenofovir } \\
\hline $50 \%$ level & 30 & 29.81 & 99.38 & \multirow{3}{*}{99.16} \\
\hline $100 \%$ level & 60 & 59.83 & 99.71 & \\
\hline $150 \%$ level & 90 & 88.54 & 98.38 & \\
\hline
\end{tabular}

\begin{tabular}{|c|c|c|c|c|}
\hline \multirow[t]{2}{*}{ Parameter } & \multicolumn{4}{|c|}{ RESULTS } \\
\hline & Emtricitabine & Elvitegravir & Cobicistat & Tenofovir \\
\hline \multicolumn{5}{|c|}{ Repeatability } \\
\hline Mean \%RSD of Retention time & 0.13 & 0.07 & 0.05 & 0.03 \\
\hline Mean \%RSD of Peak Area & 0.11 & 0.09 & 0.55 & 0.19 \\
\hline Mean \% Assay & 100.26 & 99.52 & 99.45 & 99.09 \\
\hline \multicolumn{5}{|c|}{ Reproducibility } \\
\hline Mean \%RSD of Retention time & 0.12 & 0.06 & 0.15 & 0.34 \\
\hline Mean \%RSD of Peak Area & 0.25 & 0.65 & 0.06 & 0.21 \\
\hline Mean \% Assay & 100.63 & 99.52 & 99.21 & 99.21 \\
\hline \multicolumn{5}{|c|}{ Intermediate Precision } \\
\hline Mean \%RSD of Retention time & 0.28 & 0.09 & 0.09 & 0.09 \\
\hline Mean \%RSD of Peak Area & 0.23 & 0.12 & 1.82 & 0.10 \\
\hline Mean \% Assay & 99.23 & 99.63 & 99.10 & 99.12 \\
\hline
\end{tabular}




\begin{tabular}{|c|c|c|c|c|}
\hline \multicolumn{2}{|c|}{ Table 5. Regression equation parameters } \\
\hline Parameter & Emtricitabine & Elvitegravir & Cobicistat & Tenofovir \\
\hline Linearity range(mcg/ml) & 10 to 60 & 7.5 to 45 & 7.5 to 45 & 15 to 90 \\
\hline Correlation co-efficient & 0.9992 & 0.9999 & 0.9999 & 0.9998 \\
\hline Slope & 31567 & 39259 & 4807.9 & 7077.8 \\
\hline Y-intercept & 361947 & 548607 & 113788 & 209511 \\
\hline
\end{tabular}

\begin{tabular}{|c|c|c|c|}
\hline \multicolumn{3}{|c|}{ Table 6: Assay Results } \\
\hline Drug & Labelled Amount (mg/tab) & Amount found (mg/tab) & \% of Assay \\
\hline Emtricitabine & 200 & 197.75 & 98.88 \\
\hline Elvitegravir & 150 & 149.74 & 99.83 \\
\hline Cobicistat & 300 & 150.6 & 100.38 \\
\hline Tenofovir & 150 & 299.3 & 99.77 \\
\hline
\end{tabular}

\begin{tabular}{|c|c|c|c|c|c|c|c|c|}
\hline \multicolumn{7}{|c|}{ Table 7: Forced degradation and stability } \\
\hline Condition & Emtricitabine & \%Rec & Elvitegravir & \%Rec & Cobicistat & \%Rec & Tenofovir & \%Rec \\
\hline acid & 1502999 & 94.09 & 1742470 & 99.12 & 248420 & 96.67 & 15271 & 2.39 \\
\hline base & 1396666 & 87.43 & 1636263 & 94.96 & 246022 & 95.69 & 544608 & 85.22 \\
\hline perox & 1566195 & 98.05 & 1796023 & 99.23 & 258272 & 100.45 & 593245 & 92.83 \\
\hline heat & 1534048 & 96.03 & 1797641 & 99.32 & 260419 & 94.48 & 63946 & 10.06 \\
\hline UV & 1494981 & 95.39 & 1728485 & 100.31 & 252313 & 98.14 & 595357 & 93.16 \\
\hline
\end{tabular}
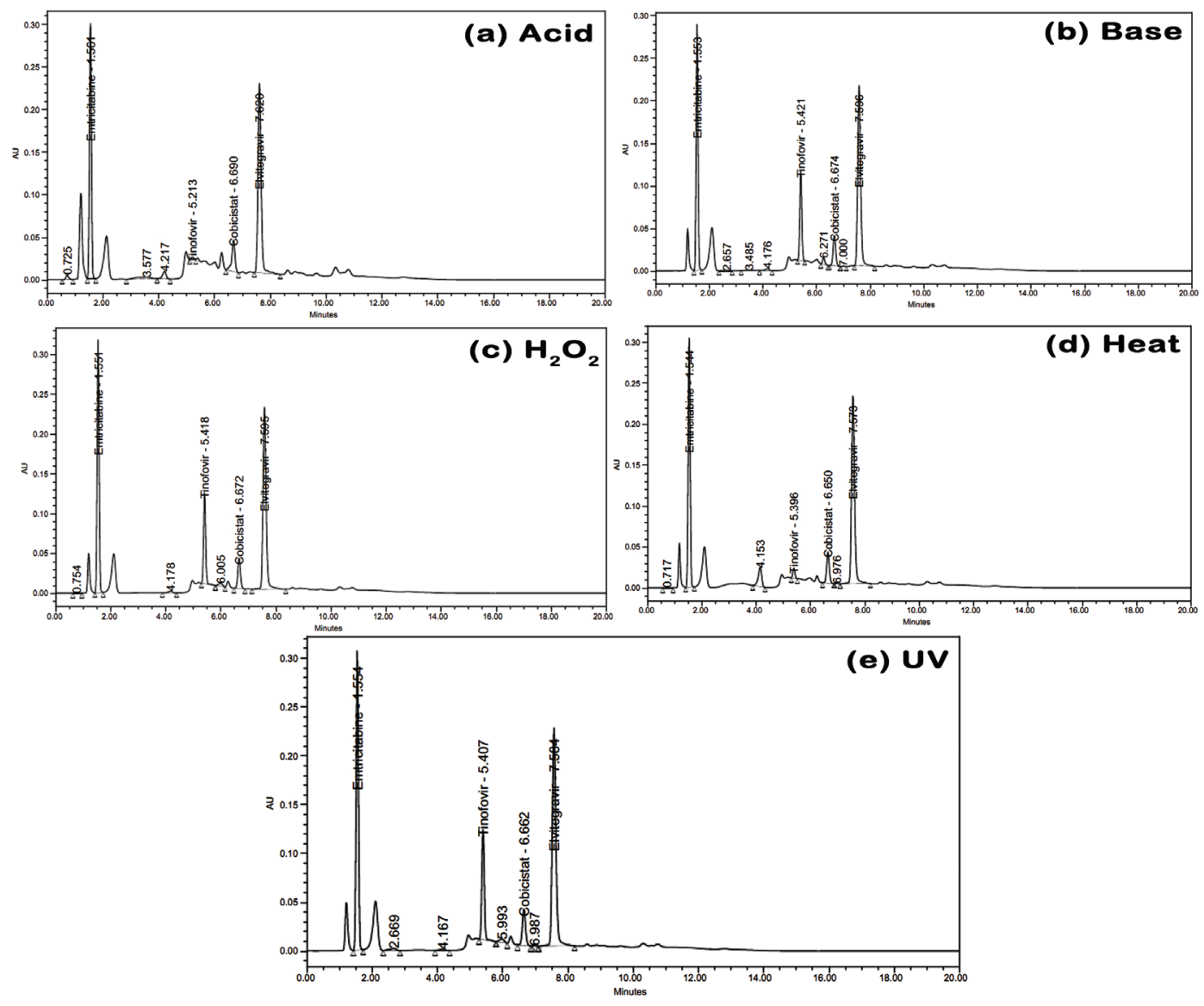

Figure 4: Degradation chromatograms of (a) Acid, (b) Base, (c) $\mathrm{H}_{2} \mathrm{O}_{2}$, (d) Heat and (e) UV 
The calibration curve was constructed by plotting concentration of standard solutions against mean peak areas and the regression equation was computed. The summary of the parameters shown in Table 5 .

\section{Detection limit ( $D L)$ and quantitation limit (QL)}

Estimation of DL and QL considered the acceptable signal-to-noise ratios 3:1 and 10:1 respectively. The limit of detection and quantitation to be determined 0.18 and $0.5455 \mu \mathrm{g} / \mathrm{ml}$ for Emtricitabine, 0.1239 and $0.3755 \mu \mathrm{g} / \mathrm{ml}$ for Elvetigravir, 0.9668 and $2.9298 \mu \mathrm{g} / \mathrm{ml}$ for Cobicistat and 0.5602 and $1.6975 \mu \mathrm{g} / \mathrm{ml}$ for Tenofovir respectively.

\section{Robustness and ruggedness}

The robustness of the method was unaffected when small, deliberate changes in the chromatographic conditions like, flow change, mobile phase composition, column temperature were performed at $100 \%$ test concentration.

The ruggedness of the proposed method studied under different columns, analyst, instrument, laboratories analysis of the same sample.

\section{Standard solution stability}

The stability of the standard solution was to test for an intervals 24 and 48 hours at room temperature. There were no significant changes observed in the system suitable parameters like theoretical plates, tailing factors, retention time and resolution. Hence the standard solution is stable up to 48 hours of room temperature.

\section{Mobile phase stability}

The stability of the mobile phase was observed for 24 and 48 hours at room temperature. There were no sinificant changes observed in peak areas, theoretical plates, tailing factors, retention time and resolution. Hence the mobile phase was stable up to 48 hours of room temperature.

\section{Analysis of marketed sample}

The proposed method was applied for the analysis of Emtricitabine, Elvetigravir, Cobicistat and Tenofovir in tablet dosage forms, the results were found to be between 99 and 101\%, the results were summarized in Table 6.

\section{Forced degradation and stability-indicating tests}

\section{Stock solution}

Weighed accurately working standards equivalent to 20 mg Emtricitabine, 15 mg Elvetigravir, 15 mg Cobcistat and $30 \mathrm{mg}$ Tenofovir into $50 \mathrm{ml}$ volumetric flask, added $30 \mathrm{ml}$ of diluent and dissolved, further made the volume with the diluent. Results of Forced degradation was shown in Table 7. Figure 4 (a-e) shows the chromatograms of forced degradation studies.

\section{Acidic degradation}

$10 \mathrm{ml}$ of $1 \mathrm{~N} \mathrm{HCl}$ added to $10 \mathrm{ml}$ of stock solution and was kept at $80^{\circ} \mathrm{C}$ for about 12 hours in water bath, cool made up the volume $100 \mathrm{ml}$ with mobile phase. Filtered the solution through 0.22 micron membrane filter.

\section{Alkali degradation}

$10 \mathrm{ml}$ of $0.5 \mathrm{~N} \mathrm{NaOH}$ added to $10 \mathrm{ml}$ of stock solution and was kept at $80^{\circ} \mathrm{C}$ for about $48 \mathrm{hrs}$ in water bath, cool made up the volume $100 \mathrm{ml}$ with mobile phase. Filtered the solution through 0.22 micron membrane filter.

\section{Oxidative degradation}

$5 \mathrm{ml}$ of $3 \% \mathrm{H}_{2} \mathrm{O}_{2}$ added to $10 \mathrm{mls}$ of stock solution and was kept at $80^{\circ} \mathrm{C}$ for about 24 hours in water bath, cool made up the volume $100 \mathrm{ml}$ with mobile phase. Filtered the solution through 0.22 micron membrane filter.

\section{Thermal degradation}

To $10 \mathrm{ml}$ of stock solution and was kept at $70^{\circ} \mathrm{C}$ for about 10 days, cool made up the volume $100 \mathrm{ml}$ with mobile phase. Filtered the solution through 0.22 micron membrane filter.

\section{CONCLUSION}

A simple, specific and reliable isocratic HPLC-DAD method was developed for the estimation of Emtricitabine, Elvetigravir, Cobicistat and Tenofovir in their pharmaceutical formulation. The four compounds were subjected to forced degradation applying several stress conditions. The proposed method was successfully separated all the compounds with degradants, estimate the active contents. The Proposed method is specific and stability-indicating power. Hence the developed method can be adapted to regular quality control analysis.

\section{ACKNOWLEDGEMENT}

The authors are thankful to $\mathrm{M} / \mathrm{s}$ Richer Pharmaceuticals, Hyderabad for providing standards and lab facilities. The authors are also thankful to Department of pharmaceutical Analysis, J.N.T. University, Kakinada, Department of Pharmaceutical Analysis and Quality Assurance, Andhra University, Vishakhapatnam, India for encouragement. 


\section{REFERENCES}

1. Budawari S, the Merck Index, $13^{\text {th }}$ Edition, Merck and Co. Inc. 2001, Whitehouse Station. NJ, p 630, 1631-32.

2. Martindale, the Complete Drug Reference, 2002, 33rd Edition, Pharmaceutical Press, London, p 620, 642.

3. Gish R G, Trinh H, Leung N, Chan F K L, Fried M L, Wright T L, Wang C, Anderson J, Mondou E, Snow A, Sorbel J, Rousseau F, Corey L. Safety and antiviral activity of emtricitabine (FTC) for the chronic hepatitis B infection: a two-year study. 2005, J Hepatol 43(1): 60-6.

4. Kavitha, K. Y.; Geetha, G.; Hariprasad, R.; Venkatnarayana, R.; Subramanian, G., Development and validation of RP-HPLC analytical method for simultaneous estimation of Emtricitabine, Rilpivirine, Tenofovir disoproxyl fumarate Disoproxil Fumarate and its pharmaceutical dosage forms, Pharmacie Globale; Jan2013, Vol. 4 Issue 1, p1.

5. Thaczuk, Derek and Carter, Michael. ICAAC: Best response to elvitegravi seen when used with T-20 and other active agents Aidsmap.com. 19 Sept. 2007.

6. $\mathrm{ICH}$ guidelines, Validation of Analytical Procedures: Text and Methodology, Q2 (R1) Nov 2005

7. http://www.drugbank.ca/drugs/DB00300 browsed on 29th June 2015.

8. Gilead Sciences, Inc. Prescribing Information. Revised: November 2012. Deeks SG, Barditch-Crovo P, Lietman PS, et al. (September 1998). Antimicrob. Agents Chemother. 42 (9): 2380-4. Highleyman, L. Elvitegravir "Quad" Single-tablet Regimen Shows Continued HIV Suppression at 48 Weeks. HIV and Hepatitis.com

9. Lepist, E. -I.; Phan, T. K.; Roy, A.; Tong, L.; MacLennan, K.; Murray, B.; Ray, A. S. (2012). "Cobicistat Boosts the Intestinal Absorption of Transport Substrates, Including HIV Protease Inhibitors and GS-7340, in Vitro". Antimicrobial Agents and Chemotherapy 56 (10): 5409-5413. doi:10.1128/ AAC.01089-12. PMC 3457391. PMID 22850510

10. Raju N, Begum S. Simultaneous RP-HPLC method for the estimation of the emtricitabine, tenofovir disoproxil fumerate and efavirenz in tablet dosage forms. Res J Pharm Tech 2008;1:522-5

11. U.S. Food and Drug Administration. United States: New Approved Drugs, Inc.; c2007-08. Available from: http://www.aegis.org/news/fda/2009/ FD090901.html. [Last updated on 2008 Sep 04; Last cited on 2011 Oct 09]

12. V. Jullien, J. M. Tréluyer, G. Pons, and E. Rey, "Determination of tenofovir in human plasma by high-performance liquid chromatography with spectro $\square$ uorimetric detection," Journal of Chromatography B, vol. 785 , no. 2, pp. 377-381, 2003

13. N. L. Rezk, R. D. Crutchley, and A. D. M. Kashuba, "Simultaneous quanti $\square$ cation of emtricitabine and tenofovir in human plasma using highperformance liquid chromatography after solid phase extraction," Journal of Chromatography B, vol. 822, no. 1-2, pp. 201-208, 2005.

14. T. Delahunty, L. Bushman, and C. V. Fletcher, "Sensitive assay for determining plasma tenofovir concentrations by LC/MS/MS," Journal of Chromatography B, vol. 830, no. 1, pp.6-12, 2006.

15. M. E. Barkil, M. C. Gagnieu, and J. Guitton, "Relevance of a combined UV and single mass spectrometry detection for the determination of tenofovir in human plasma by HPLC intherapeutic drug monitoring," Journal of Chromatography B, vol. 854, no. 1-2, pp. 192-197, 2007.

16. N. A. Gomes, V. V. Vaidya, A. Pudage, S. S. Joshi, and S. A. Parekh, "Liquid chromatography-tandem mass spectrometry (LC-MS/MS) method for simultaneous determination of Tenofovir and emtricitabine in human plasma and its application to a bioequivalence study," Journal of Pharmaceutical and Biomedical Analysis, vol. 48, no. 3, pp. 918-926, 2008

17. P. B. Kandagal, D. H. Manjunatha, J. Seetharamappa, and S. S. Kalanur, "RP-HPLC method for the determination of Tenofovir in pharmaceutical formulations and spiked human plasma," Analytical Letters, vol. 41, no. 4, pp. 561-570, 2008

18. D. Ashena, A. Verbeek, J. Hoogmartens, and E. Adams, "Development and validation of an LC method for the determination of emtricitabine and related compounds in the drugsubstance," Journal of Separation Science, vol. 32, no. 11, pp. 823-1830, 2009

19. R. W. Sparidans, K. M. L. Crommentuyn, J. H. M. Schellens, and J. H. Beijnen, "Liquid chromatographic assay for the antiviral nucleotide analogue tenofovir in plasma using derivatization with chloroacetaldehyde," Journal of Chromatography B, vol. 791, no. 1-2, pp. 227-233, 2003.

20. U. Seshachalam, B. Haribabu, and K. B. Chandrasekhar, "Development and validation of a stability-indicating liquid chromatographic method for determination of emtricitabine and related impurities in drug substance," Journal of Separation Science, vol. 30, no. 7, pp. 999-1004, 2007

21. R. P. Weissburg, E. R. Montgomery, L. A. Junnier, J. Segretario, S. Cook, and P. K. Hovsepian, "Investigation of critical factors for the resolution of SR695, a key impurity, from efavirenz in the reversed-phase assay of efavirenz dosage forms," Journal of Pharmaceutical and Biomedical Analysis, vol. 28, no. 1, pp. 45-56, 2002.

22. S. Mogatle and I. Kanfer, "Rapid method for the quantitative determination of efavirenz in human plasma," Journal of Pharmaceutical and Biomedical Analysis, vol. 49, no. 5, pp.1308-1312, 2009.

23. E. R. Montgomery, A. L. Edmanson, S. C. Cook, and P. K. Hovsepian, "Development and validation of a reversephase HPLC method for analysis of efavirenz and its related substances in the drug substance and in a capsule formulation," Journal of Pharmaceutical and Biomedical Analysis, vol. 25, no. 2, pp. 267-284, 2001.

24. U. Seshachalam, D. V. L. Narasimha Rao, and K. B. Chandrasekhar, "Validated enantiospecifc LC method for determination of (R)-enantiomer impurity in (S)-efavirenz," Pharmazie, vol. 63, no. 2, pp. 107-109, 2008.

25. M. Joshi, A. P. Nikalje, M. Shahed, and M. Dehghan, "HPTLC method for the simultaneous estimation of emtricitabine and tenofovir in tablet dosage form," Indian Journal of Pharmaceutical Sciences, vol. 71, no. 1, pp. 95-97, 2009.

26. N. Kaul, H. Agrawal, A. R. Paradkar, and K. R. Mahadik, "be international conference on harmonisation guidance in practice: stress degradation studies on lamivudine and development of a validated specific stabilityindicating HPTLC assay method," Chromatographia, vol. 60, no. 3-4, pp. 213-221, 2004

27. N. A. Raju and S. Begum, "Simultaneous RP-HPLC method for the estimation of the emtricitabine, tenofovir disoproxyl fumerate and efavirenz in tablet dosage forms," Research Journal of Pharmacy and Technology, vol. 1, pp. 522-525, 2008.

28. Mangoankar K and Desai A (2008) Simultaneous estimation of emtricitabine, tenofovir disoproxil fumarate and efavirenz from tablets by reverse phase highperformance liquid chromatography method. Indian Drugs 45(3): 188-92.

29. Appala N R, Rao V J, Vanitha P K, Mukilteo K and Srinivasu K (2008) Simultaneous estimation of tenofovir disoproxil, emtricitabine and efavirenz in tablet dosage form by RP- HPLC. Orient J Chem 24(2): in press. 